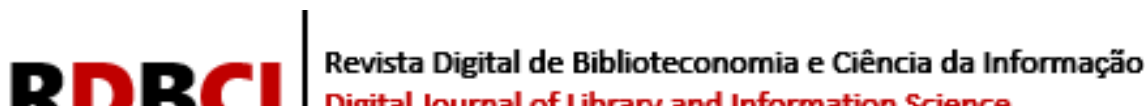 Digital Journal of Library and Information Science
}

$\mathbf{I S S}_{1678-765 x}$

क.

10.20396/rdbci.v19ioo.8665311

(c) (i) $B Y$

ARTIGO

\section{A representação temática da informação na Saúde Coletiva no contexto das palavras-chave}

\author{
Sandra Regina Moitinho Lage 1 (ID) https://orcid.org/0000-0003-4769-2975 \\ Patricia Ofelia Pereira de Almeida 2 (D) https://orcid.org/0000-0002-9830-9465 \\ Rosane Suely Alvares Lunardelli 3 (D) https://orcid.org/0000-0002-5405-072X \\ ${ }^{1}$ Universidade Estadual de Londrina, Londrina, PR, Brasil / e-mail: sanlage2012@gmail.com \\ ${ }^{2}$ Universidade Estadual de Londrina, Londrina, PR, Brasil / e-mail: pereira@uel.br \\ ${ }^{3}$ Universidade Estadual de Londrina, Londrina, PR, Brasil / e-mail: Iunardelli@uel.br
}

\begin{abstract}
RESUMO
Introdução: Diante da quantidade de estudos que constituem um campo de conhecimento, indica-se a importância da representação informacional de suas temáticas e por conseguinte, a disseminação dos conhecimentos produzidos. Objetivos: Identificar as palavras-chave utilizadas em dissertações do campo da saúde coletiva, apresentar as mais empregadas e analisar o conteúdo temático que as constituem. Metodologia: Optou-se pela pesquisa bibliográfica, documental e descritiva, de natureza quantiqualitativa, fundamentada nos aportes teóricos e metodológicos da representação temática da informação, para identificar as palavras-chave dos noventa e um trabalhos de mestrado, aprovados pelo Programa de Pós-Graduação em Saúde Coletiva da Universidade Estadual de Londrina no período de 2010 a 2020. Resultados: Dentre as palavras-chave mais empregadas - Atenção Primária à Saúde (APS), trata-se da mais recorrente. Conclusão: Ao identificar e analisar as palavras-chave, ratifica-se o compromisso do campo da saúde coletiva, em especial do Programa de Pós-Graduação em Saúde Coletiva da Universidade Estadual de Londrina, que prioriza a promoção, a prevenção e a proteção da saúde com vistas ao bemestar da população. Destaca-se, o papel da Ciência da Informação, dos estudos relacionados à organização e a representação da informação, com vistas a recuperação e a socialização da informação científica.
\end{abstract}

PALAVRAS-CHAVE: Saúde coletiva. Ciência da informação. Representação temática da informação.

\section{Thematic representation of Collective Health information in the context of keywords}

\begin{abstract}
Introduction: Given the number of studies that constitute a field of knowledge, the importance of the informational representation of its themes is indicated, and consequently, the dissemination of the knowledge produced. Objectives: To identify the keywords used in dissertations in collective health, to present the most used ones and to analyze their thematic content. Methodology: Bibliographic, document and descriptive research was used, of a quanti-qualitative nature, based on the theoretical and methodological contributions of thematic representation of information, to identify the keywords of ninety-one master's papers, approved by the Postgraduate Program in Collective Health at the Londrina State University from 2010 to 2020. Results: Among the most employed keywords - Primary Health Care (PHC), it is the most recurrent. Conclusion: By identifying and analyzing the keywords, the commitment of the collective health field is ratified, especially the Postgraduate Program in Collective Health at the
\end{abstract}




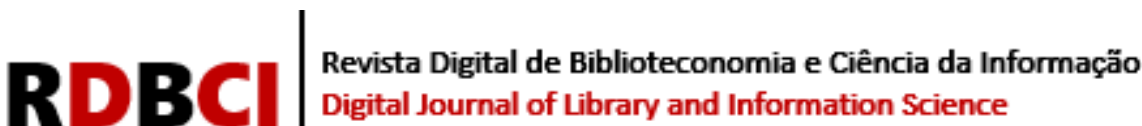

Londrina State University, which prioritizes the promotion, prevention and protection of health with a view to the well-being of the population. The role of Information Science is highlighted, of studies related to the organization and representation of information, aiming at the recovery and socialization of scientific information.

KEYWORDS: Collective health. Information science. Thematic representation of information.

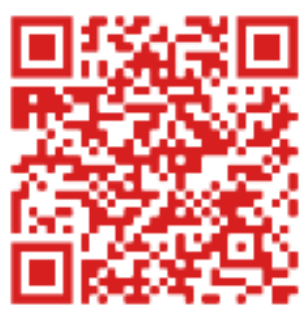

JITA: BH. Information needs and information requirements analysis. 


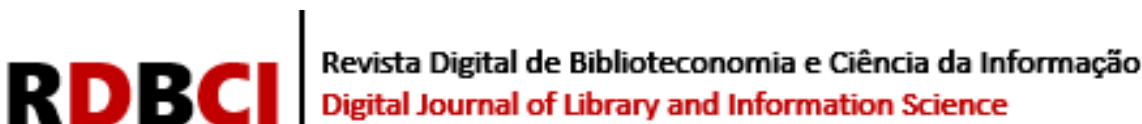

\section{INTRODUÇÃO}

O conhecimento científico, cada vez mais, tem propiciado expressivas quantidades e variedades de informações, as quais, requerem tratamento informacional para que haja a veiculação de novos conhecimentos, instituindo, dessa forma, a "[...] rotina natural da própria ciência" (CINTRA et al. 2002, p. 21). Dentre os diversos contextos informativos, seguindo Población e Noronha (2002, p. 98), observa-se que os programas de pós-graduação, tornaramse polo gerador da produção científica no Brasil. Dessa forma, entende-se que esses programas são ambientes ricos de oportunidades de aprendizagem, de aquisição de conhecimento, impulsionadores do processo de ensino e pesquisa, considerando sua permanente dimensão social e coletiva.

Wersig e Neveling (apud BELKIN; ROBERTSON, 1973) ressaltam a responsabilidade social implícita na transmissão do conhecimento ao evidenciarem a contribuição da Ciência da Informação $(\mathrm{CI})$ na organização e na representação da informação, por meio de processos de tratamento documentário, visando a identificação do que é essencial, com vistas à disseminação e recuperação da informação. Borba, Van der Laan e Chini (2012) esclarecem que o tratamento temático tem como objetivo estabelecer a representação informacional do conteúdo de um documento, com o intuito de possibilitar a recuperação e acesso à informação. Considera-se, nesse sentido, os resumos, as palavras-chave, sínteses informacionais que representam tematicamente o texto que os originou.

Dentre esses microtextos ressalta-se que as palavras-chave possibilitam e facilitam a identificação do conteúdo de um trabalho científico, ou seja, a representação temática das informações vinculadas ao texto, evidenciando a preocupação em intermediar e apoiar aos que necessitam apropriar-se de um determinado recurso informacional. A busca por trabalhos científicos, realizada por meio de palavras-chave, oportunizam a localização de textos pertinentes às necessidades informacionais dos pesquisadores.

Nessa perspectiva, cabe mencionar a atuação da pós-graduação em Saúde Coletiva, formando mestres e doutores, capacitando-os, não somente em construir conhecimento, mas também apresentar o conhecimento existente (LOYOLA, 2012). Vista como um campo de produção de saberes, assim como de práticas, por meio de seu caráter interdisciplinar, manifesta-se e articula-se o processo saúde-doença no contexto populacional. Diante do cenário apresentado, considerando a relevância dos estudos da Saúde Coletiva, entende-se que os assuntos abordados pelo campo precisam ser disseminados para a sociedade em geral. Nesse sentido, questiona-se: como se dá a representação temática dos conteúdos das dissertações, tendo como elemento representativo as palavras-chave, atribuída pelos autores em seus trabalhos de conclusão? Em busca de respostas, recorreu-se aos preceitos da organização e representação oriundos da Ciência da Informação.

Nessa direção, o artigo tem como objetivo, identificar as palavras-chave utilizadas em dissertações do campo da saúde coletiva, apresentar as mais empregadas e analisar o conteúdo temático que as constituem. Ao analisar as palavras-chave mais empregadas, sustenta-se a premissa de que será possível identificar os assuntos mais abordados nas pesquisas desenvolvidas pelo programa de pós-graduação, apresentando aos estudiosos da área não somente informações a respeito dos estudos realizados, como também a necessidade de pesquisas relacionadas as temáticas pouco estudadas.

De uma perspectiva metodológica, optou-se pela pesquisa bibliográfica, documental e descritiva, de natureza quantiqualitativa, fundamentada nos aportes teóricos e metodológicos da representação temática da informação, para identificar as palavras-chave dos noventa e um trabalhos de mestrado, aprovados pelo Programa de Pós-Graduação em Saúde Coletiva da 


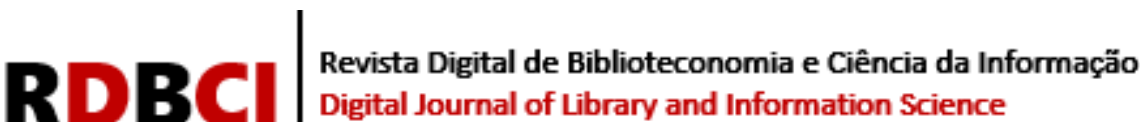

Universidade Estadual de Londrina no período de 2010 a 2020. Importa esclarecer que essa proposta originou-se no bojo do projeto de pesquisa denominado Metarrepresentações Informacionais em Ciência da Informação, do Programa de Pós-Graduação de Ciência da Informação da Universidade Estadual de Londrina (PPGCI UEL), lócus de discussões e reflexões acerca da multiplicidade temática das pesquisas no âmbito da Saúde Coletiva e a necessidade de organizá-las por intermédio de suas representações temáticas, visando a recuperação desses relevantes recursos informacionais.

\section{O CAMPO DA SAÚDE COLETIVA}

A Saúde Coletiva pode ser considerada como "[...] campo de conhecimento de natureza interdisciplinar cujas disciplinas básicas são epidemiologia, o planejamento/administração de saúde e as ciências sociais em saúde" (PAIM; ALMEIDA FILHO, 2000, p.63). Assim, definida como uma invenção brasileira, o termo Saúde Coletiva está presente na agenda acadêmica e política, trata-se de abordagens das relações entre:

conhecimentos, práticas e direitos referentes à qualidade de vida. Em lugar das tradicionais dicotomias - saúde pública/assistência médica, medicina curativa/medicina preventiva, e mesmo indivíduo/sociedade - busca-se uma nova compreensão na qual a perspectiva interdisciplinar e o debate político em torno de temas como universalidade, eqüidade, democracia, cidadania e, mais recentemente, subjetividade emergem como questões principais. (LIMA; SANTANA, 2006, p. 9).

Dentre os principais fatos ocorridos na política de saúde no Brasil, desde o século XX, destaca-se o movimento pela Reforma Sanitária Brasileira, na década de 1970. Na época, a expressão Saúde Coletiva, foi empregada como referência ao conjunto de ideias em relação, com mudanças e transformações pertinentes e necessárias na área da saúde. Mudanças que abarcavam o sistema e todo o setor saúde, com o propósito de buscar a melhoria das condições de vida da população. Nesse contexto, grupos de médicos e outros profissionais preocupados com a saúde pública desenvolveram teses que integraram as discussões políticas. Como propostas da Reforma Sanitária resultou-se a universalidade do direito à saúde, oficializado com a Constituição Federal de 1988 e a criação do Sistema Único de Saúde (SUS). (REFORMA..., 2020).

Importante mencionar que o processo da Reforma Sanitária Brasileira, teve como marco institucional a $8^{\text {a }}$ Conferência Nacional de Saúde, em 1986, momento que houve uma grande mobilização pela reforma do sistema de saúde e demandas do movimento sanitarista foram discutidas e aprovadas. Nesse cenário, estabeleceu-se "fortalecer o setor público de saúde, expandir a cobertura a todos os cidadãos e integrar a medicina previdenciária à saúde pública, constituindo assim um sistema único" (PAIVA; TEIXEIRA, 2014, p. 25).

De acordo com as diretrizes que nortearam o processo da Reforma Sanitária Brasileira, descreve Teixeira (2009, p. 476), "O movimento que impulsionou a Reforma Sanitária Brasileira colocou como projeto a construção contra-hegemônica de um novo patamar civilizatório, o que implica uma profunda mudança cultural, política e institucional capaz de viabilizar a saúde como bem público". Nesse cenário, alcançando maiores níveis de institucionalidade no país, criava-se a Associação Brasileira de Saúde Coletiva (ABRASCO) "como forma de organização dos programas de pós-graduação no campo da saúde pública, da medicina social e da saúde coletiva" (PAIVA; TEIXEIRA, 2014, p. 22).

A saúde coletiva surgiu em um momento de organização do sistema público de saúde, no sentido de ampliá-lo e estendê-lo a toda a população do país. Demonstra-se no termo, "saúde 


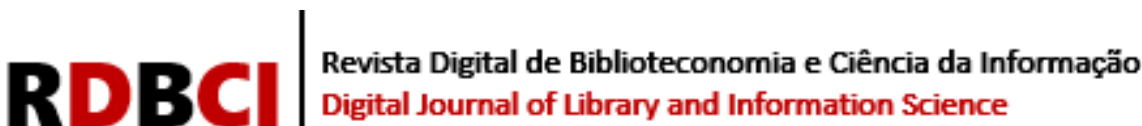

coletiva", a presença das ciências sociais e das ciências humanas, evocando assim, estudos da saúde de uma coletividade, "que constitui e alicerça a área". (LOYOLA, 2012, p. 9). Enquanto Pós-Graduação pode-se constatar que a Saúde Coletiva, institui-se, segundo Guimarães (2019, p.114), em um campo de conhecimentos e de práticas que a partir de sua consistência e potência provocam mudanças no plano do conhecimento da pluralidade de vozes reformistas. Desse ponto de vista, observa Guimarães (2019), que a problematização do coletivo inserida na saúde coletiva, configura-se um caminho a se refletir acerca do movimento sanitário no contexto atual.

\section{Pós-Graduação em Saúde Coletiva}

A necessidade de atualização e capacitação profissional é uma constatação, principalmente na sociedade contemporânea da segunda metade do século XX e mais ainda neste século XXI. Nesse sentido, os profissionais estão buscando a educação continuada para acompanhar a evolução, tanto em suas áreas de conhecimentos como nas áreas correlatas. Nesse sentido as organizações têm se preocupado em oferecer oportunidades de capacitação, Stricto sensu. Destaca-se nesse contexto, a pós-graduação em saúde coletiva.

A pós-graduação, Stricto sensu, é considerada um programa bem-sucedido na educação brasileira. "Desde seu início, foi formulado com o propósito específico de contribuir para o desenvolvimento nacional por meio da formação de docentes e pesquisadores com competências para a pesquisa" (NOVAES, et al. 2018, p. 2019).

Essa ideia, se reflete nos trabalhos científicos, em especial, nos textos de dissertações, que englobam significativa produção acadêmica, ancoradas na realidade, com propósito transformador. Nesse sentido, o envolvimento de pesquisadores no campo da Saúde Coletiva, considerando a riqueza de seu caráter interdisciplinar, capacita estudiosos a enfrentar os mais complexos objetos de investigação em saúde, transformando conhecimento em ação (BARRETO, 2003). A Saúde Coletiva, por meio de seus conteúdos temáticos e suas decorrentes propostas de ação, contribui com o estudo do processo social conhecido como saúde-doença, no âmbito coletivo. A Saúde Coletiva, entretanto, vai além do processo saúde e doença. Referese também, as questões administrativas e logísticas, da necessidade de identificar ações preventivas de saúde da população.

De acordo com essa perspectiva, entende-se que os produtos gerados pelos Programas de Pós-Graduação em Saúde Coletiva, merecem tratamento informacional adequado para que cumpram suas funções como geradores de novos conhecimentos e especialmente com propostas do campo, para fortalecer o Sistema Único de Saúde (SUS), com vistas a melhoria da saúde pública brasileira.

Reconhece-se que o registro dos temas e assuntos gerados por trabalhos científicos é o modo pelo qual as instituições de ensino superior, vistas como centros sistematizados do conhecimento, se fazem presentes no saber fazer e no poder da ciência. Nesse sentido, recorrese a Ciência da Informação, pois as informações oriundas das pesquisas científicas norteiam a tomada de decisão não somente no cenário administrativo, mas sobretudo no atendimento à população. Portanto, torna-se claro que essas informações devem estar organizadas para que sejam recuperadas pela sociedade em geral, quando necessário. 


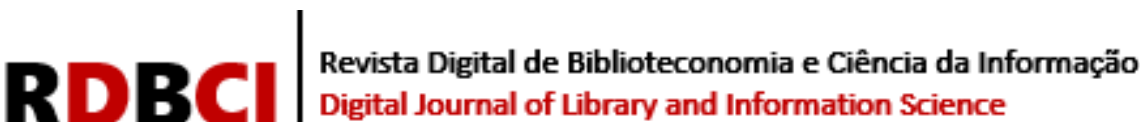

\section{ORGANIZAÇÃO E A REPRESENTAÇÃO DA INFORMAÇÃO}

A Ciência da Informação, se constitui como área que percorre diferentes campos do saber e que tem entre suas características o papel de investigar as propriedades e o comportamento da informação, especificamente os meios para sua organização (ARAÚJO JÚNIOR, 2007). Ressalta-se a importante contribuição dos aportes teóricos e metodológicos da organização e da representação da informação, que constituem-se como importantes eixos da área. Dessa forma, organizar e representar a informação, para que seja passível de recuperação, acesso e apropriação, remete a uma análise de campos interdisciplinares, na qual consolida-se a Ciência da Informação como principal representante. Evidencia-se assim, a necessidade de produzir informação com a finalidade de identificar os registros existentes nos diversos campos do conhecimento. Salienta-se, que o conhecimento produzido nas mais diversas áreas, desvela a necessidade de aperfeiçoar propostas que contribuam para a organização da informação. Logo, a organização da informação tem se constituído em um importante campo de estudos para a Ciência da Informação. Victorino e Bräscher (2009) lembram que a informação pode ser registrada em vários tipos de documentos (livros, relatórios, fotografias, entre outros). Esses documentos e seus conteúdos, são denominados objetos informacionais. De acordo com Victorino e Bräscher (2009, p. 2), “[...] o objetivo da organização da informação é dar suporte ao fluxo de tratamento e recuperação dos objetos informacionais estruturados, semi-estruturados e não estruturados nas organizações." Diante disso, Bräscher e Café $(2008$, p. 2) esclarecem que, “[...] geralmente, quando se organiza a informação, se tem em vista o usuário final de um sistema de informação, que recorre ao sistema para satisfazer uma necessidade específica de informação."

A organização da informação, para Café e Sales (2010), “[...] é um processo de arranjo de acervos tradicionais ou eletrônicos realizados por meio da descrição física e de conteúdo (assunto) de seus objetos informacionais." O processo de organização da informação tem como objetivo possibilitar o acesso ao conhecimento compreendido na informação. Ao enfocar a organização, representação e preservação da informação registrada, a Ciência da Informação tem como escopo "[...] organizar a informação para entendê-la melhor e, desta forma, recuperála de forma mais eficiente" (CAFÉ, SALES, 2010, p. 126).

Para Novellino (1996, p. 38), o estudo da representação da informação sob a ótica de seu conteúdo caracteriza-se como "[...] a substituição de uma entidade linguística longa e complexa - o texto do documento - por sua descrição abreviada." Segundo a autora, o uso de tal sumarização, ou substituição, não é somente uma consequência de restrições quanto à diminuição de volume de material a ser armazenado e pesquisado, mas, sobretudo, sua função está em demonstrar, em poucas palavras, a essência do documento. Nessa linha de raciocínio, representar, na perspectiva de Peirce (2008, p. 61), é "Estar em lugar de, isto é, estar numa tal relação com um outro que, para certos propósitos, é considerado por alguma mente como se fosse esse outro." Assim, considera-se, que o grande diferencial da representação da informação, além de produzir diversas maneiras de significar e de ressignificar o documento, "o fato de se poder atuar em distintos domínios, realizando as diferentes investigações a partir do prisma da representação da informação" (ALBUQUERQUE; GAUDÊNCIO; SANTOS, 2019, p. 23).

No campo da Ciência da Informação, a expressão tratamento da informação pode englobar processos que envolvem as descrições físicas e temáticas dos documentos em unidades de informação ou sistemas de recuperação da informação, bem como o desenvolvimento de instrumentos utilizados nessas descrições e, também, a implantação de estruturas físicas destinadas ao armazenamento das informações (DIAS; NAVES, 2013). 


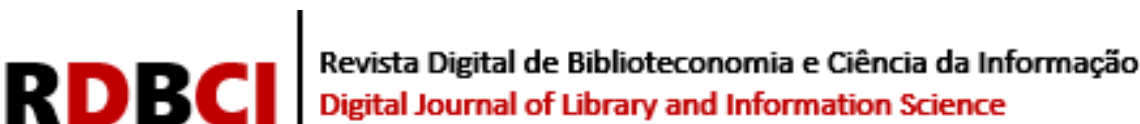

De acordo com essa linha de raciocínio, o processo de tratamento da informação, pode ser dividido em: representação descritiva, com o objetivo de identificar aspectos extrínsecos de um documento, tais como o autor e o título e de componentes da mesma natureza e representação temática, que tem como finalidade ressaltar o assunto do documento. A representação temática é vista como a base para a organização da informação e do conhecimento, são técnicas para análise de um documento, identificando os temas nele tratados. Destaca-se que a representação temática tem como função a extração ou associação de assuntos que melhor representam os conteúdos e as temáticas registradas nos documentos. A representação temática da informação, se efetiva por meio de palavras-chave, descritores, termos, resumos, entre outros. (RABELO; PINTO, 2019).

Nas palavras de Dias e Naves (2013, p. 7), a representação temática, [...] "visa caracterizar o documento do ponto de vista do seu conteúdo". Em decorrência, segundo os autores, no âmbito da Ciência da Informação, a representação temática se caracteriza por intermédio de procedimentos também denominados de análise de assunto, análise temática, análise documental, análise de informação, entre outras designações, tendo como propósito elaborar produtos representativos informacionais, como por exemplo, os registros bibliográficos e catalográficos, resumos, palavras-chave, descritores, entre outros.

\section{A PALAVRA-CHAVE COMO ELEMENTO REPRESENTATIVO}

A inserção de palavra-chave em trabalhos científicos, decorre da sua importância como forma de descrição ou apresentação, de forma sintética, das informações ali apresentadas, tornando-se então, como fator preponderante com relação a recuperação desses recursos informacionais. Com o intuito de facilitar e categorizar o conteúdo, dentro de uma gama de assuntos, Borba, Van der Laan e Chini (2012, p. 27) esclarecem que "palavra-chave é caracterizada por ser atribuída pelo autor [...], com o objetivo de representar sinteticamente o conteúdo temático do texto."

Nesse sentido, Fujita (2004, p. 258) observa que para a determinação de palavra-chave deve-se ter por parte do autor "uma visão sobre o texto e a organização de seu conteúdo de modo a representá-lo conforme seu assunto principal". Segundo a autora, (2004, p. 257), o significado de uma palavra-chave deve estar intimamente ligado à temática do texto, "da mesma forma como se pudéssemos encapsular todo o conteúdo de um texto em uma palavra-chave. Desse modo, determinar palavras-chave de modo a representar o conteúdo de um texto para uma futura recuperação é, certamente, uma operação que envolve conhecimento sobre o assunto do texto (FUJITA 2004, p. 257).

Borba, Van der Laan e Chini (2012, p. 27), observam que a "palavra-chave tem a característica de ser livremente atribuída pelo autor de um texto, visando, assim, a representação do conteúdo informacional presente no documento por ele elaborado". Nessa linha de pensamento, reiteram que a "[...] a palavra-chave deveria ser um termo da área do conhecimento sobre o qual o autor trata. Portanto, seria uma unidade tanto de representação como de recuperação da informação.” Dentre as formas de representação da informação, a palavra-chave é a que apresenta o documento de maneira mais condensada, pois empenha-se em resumir, o máximo possível, seu conteúdo. Entende-se que essa forma de representar a informação, possibilita decidir por acessar ou não o documento completo.

Quanto a finalidade, o papel e a utilização da palavra-chave, evidencia-se Miguéis et al. (2013, p. 115) que "potencia o acesso ao conteúdo dos documentos, para além da informação que é representada pelo título e resumo; traduz o pensamento dos autores, e mantém o contacto com a realidade da prática quotidiana, acompanhando a evolução científica e tecnológica, que 


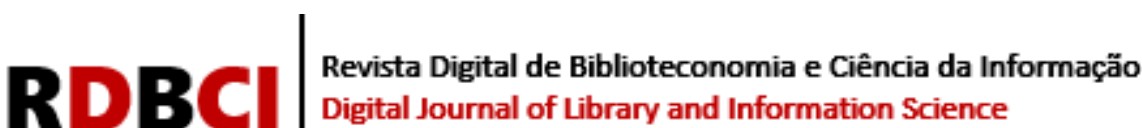

é refletida pelos documentos." Segundo Hartley e Kostoff (2003), o registro mais antigo do uso de palavras-chave foi encontrado no Journal of Applied Behavior Analisis, em 1975, mas é possível que elas já estivessem sendo utilizadas por outros periódicos anteriores a essa data. A princípio, o periódico utilizava o termo "descriptors", e com o passar do tempo passou a empregar o termo "keywords".

De acordo com Gil-Leiva e Alonso-Arroyo (2005, p. 63, tradução nossa), "as palavraschave são palavras ou frases que proporcionam informação temática ou técnica dos documentos". Nessa direção, Fujita (2004, p. 258) afirma que "A palavra-chave é uma representação do conteúdo significativo do texto e também é utilizada para representar uma necessidade de informação na estratégia de busca." Hartley e Kostoff (2003), as indicam os principais conceitos e domínios de interesse de um artigo e, portanto, juntamente com o resumo, nome do autor e título, são indispensáveis no auxílio à recuperação da informação eletrônica em qualquer banco de dados respeitável. Barreto (2008, p. 10), considera as palavras-chave como indicadores de conteúdo.

Nessa direção, conforme afirmam Rodrigues et al. (2017, p. 1065), “As palavras-chave têm uma grande importância no contexto da organização, representação e recuperação da informação e do conhecimento, porém esta acaba por adquirir um papel secundário na produção científica." Hartley e Kostoff (2003, p. 433, tradução nossa) "evidenciam ainda a importância das palavras-chave na avaliação de artigos e dos periódicos, no que diz respeito a sua representatividade na comunidade científica."

O uso de delimitadores dos termos se torna muito importante na escolha das palavraschave. Em cada época, região, cultura ou área do conhecimento pode haver diferentes termos para um mesmo significado, ou ainda, diferentes significados para um mesmo termo. Embora muitas bases de dados disponham de buscadores dinâmicos, o uso excessivo de termos distintos, para um mesmo assunto, pode acarretar dificuldade em encontrar documentos relevantes, tendo como consequência da busca um resultado muito volumoso ou reduzido.

Ainda que sejam gráfica e semanticamente distintos, muitas vezes o emprego dos termos palavras-chave e descritores são considerados intercambiáveis. Entretanto, cabe ressaltar que apesar dos dois termos estarem ligados à ideia de representar, de identificar as informações mais relevantes, as palavras-chave são decorrentes da linguagem natural do autor, retiradas do próprio texto, enquanto os descritores são termos previamente selecionados e validados por especialistas na área.

\section{PROCEDIMENTOS METODOLÓGICOS}

O universo da pesquisa constituiu-se de 91 trabalhos científicos, relacionados às dissertações defendidas e aprovadas no período de 2010 a 2020 no PPGSC/UEL. Trata-se, como anteriormente mencionado, de uma pesquisa bibliográfica e documental, descritiva, bem como um estudo quantiqualitativo. Entende-se que para o desenvolvimento do estudo qualitativo, abarca-se a ótica dada ao problema da pesquisa. Para alguns estudos há necessidade de uma abordagem múltipla para melhor ser investigada e analisada. Nesse sentido, compreende-se de uma pesquisa que busca familiaridade com o problema e assim, torná-lo explícito diante dos registros e análises, permitindo a descrição de suas características (GIL, 2017).

Considerando a constituição do corpus da pesquisa, importante mencionar que o PPGSC/UEL iniciou suas atividades com o curso de mestrado em 1990, e desde 2009 o curso em nível de doutorado foi inserido no Programa. Ao longo desses anos, o PPGSC/UEL 


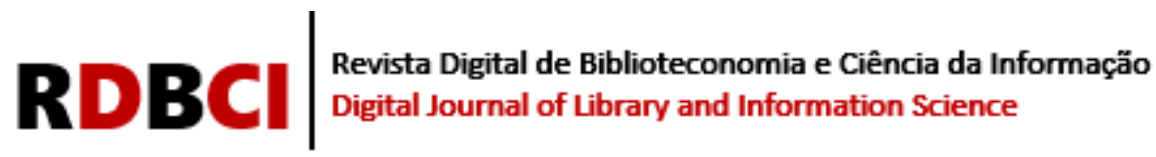

possibilita, além da capacitação de recursos humanos, a colaboração mútua entre docentes/orientadores e alunos na perspectiva de desenvolver projetos e pesquisas que contribuam para a melhoria da qualidade de vida das pessoas e comunidade e, por conseguinte, com a diversidade de abordagens temáticas que contribuem para o campo da saúde coletiva. Experiências com organização de serviços de saúde, por meio de profissionais da saúde e de docentes, influenciaram mudanças na organização e prática sanitárias locais e estaduais. Nessa linha de raciocínio, os cenários com foco na integração ensino, serviço e comunidade têm sido mantidos como eixo de trabalho, com estímulo a pesquisas que contribuam para a melhoria da gestão dos serviços de saúde e da qualidade de vida e saúde da população. Entende-se, que os produtos científicos têm como enfoque contribuir para o desenvolvimento do SUS e direcionar melhorias para o processo de saúde pública no país.

Assim sendo, para identificar as palavras-chave utilizadas em dissertações da PPGSC/UEL e apresentar as mais abordadas no período investigado, assim como analisar o conteúdo temático que as constituem sob a ótica da representação da informação, o artigo percorreu as seguintes etapas:

1) Definição do período a ser analisado, identificou-se as dissertações aprovadas, estabelecendo assim, o corpus da pesquisa;

2) Acesso aos 91 trabalhos de dissertação, localizados no site do PPGSC/UEL, que disponibiliza não somente os títulos dos trabalhos científicos (dissertações e teses), como também suas versões on-line, com o ano de ingresso do discente, orientador e data da defesa. As dissertações, também, encontram-se disponibilizadas na Biblioteca Digital da Universidade Estadual de Londrina (BD/UEL).

3) Extrair dos 91 trabalhos de dissertação, os títulos (como subsídios para a análise dos resultados) e as palavras-chave;

4) Coleta das palavras-chave dos respectivos trabalhos - identificou-se um total de 394 palavras-chave;

5) Padronização e agrupamento das 394 palavras-chave pela similaridade e semântica - resultado, um total de 241 palavras-chave;

6) Estruturar, categorizar e quantificar as palavras-chave;

7) Identificação das palavras-chave mais recorrentes e análise do conteúdo temático que as constituem no Programa de Pós-Graduação investigado do campo da Saúde Coletiva;

8) Contribuições da CI, enquanto representação temática com vistas a transferência da informação, de linguagens formalizadas, que facilitam a comunicação e a recuperação da informação.

No que tange ao percurso metodológico, a seguir são apresentadas a análise e a discussão dos resultados da pesquisa, que teve como objetivo identificar as palavras-chave utilizadas em dissertações do campo da saúde coletiva, apresentar as mais empregadas e analisar o conteúdo temático que as constituem.

\section{ANÁLISE E DISCUSSÃO DOS RESULTADOS}

Após, coletadas um total de 394 palavras-chave, realizou-se a padronização dos termos e seu agrupamento, obtendo-se como resultado o total de 241 palavras-chave. A padronização e agrupamento se fez necessário visto que, alguns assuntos foram descritos com grafias diferentes. Para tanto, demonstra-se no Quadro 1, o resultado do agrupamento, onde encontramse as palavras-chave e sua recorrência. 


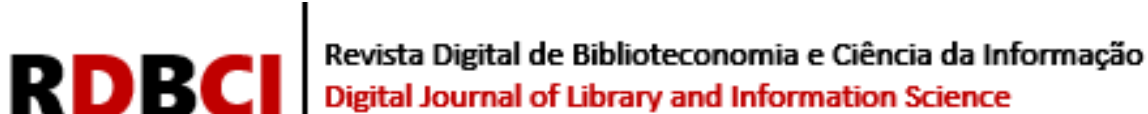

Quadro 1-Recorrência das palavras-chave

\begin{tabular}{|c|c|}
\hline PALAVRAS-CHAVE & FREQUÊNCIA \\
\hline Atenção primária à saúde. & 15 \\
\hline Docentes. & 10 \\
\hline Diabetes Mellitus; Sistema Único de Saúde. & 7 \\
\hline $\begin{array}{l}\text { Adulto; Assistência à Saúde; Cartografia; Comportamento alimentar; Gestão em saúde; } \\
\text { Regionalização; Saúde da criança; Saúde do trabalhador. }\end{array}$ & 5 \\
\hline $\begin{array}{l}\text { Avaliação em saúde; Estratégia Saúde da Família; fatores de risco; Governança; Pessoal } \\
\text { de saúde; Prevalência; Saúde bucal. }\end{array}$ & 4 \\
\hline $\begin{array}{l}\text { Acolhimento; Doenças cardiovasculares; Dor crônica; Educação continuada; Equipe de } \\
\text { Assistência ao Paciente; Estudos Longitudinais; Hipertensão; Idoso; Integralidade em } \\
\text { saúde; Mão de obra em saúde; Obesidade; Pesquisa qualitativa. }\end{array}$ & 3 \\
\hline $\begin{array}{l}\text { Absenteísmo; Acidentes de Trânsito; Administração de Serviços de Saúde; Alteraç̃̃es } \\
\text { do Peso Corporal; Apoio Matricial; Assistência Integral à Saúde; Atenção domiciliar; } \\
\text { Atenção secundária a saúde; Autoimagem; Condições de Trabalho; Consórcios de } \\
\text { saúde; Dieta; Dor; Dor musculoesquelética; Educação em Saúde; Educação física e } \\
\text { treinamento; Efeitos Colaterais e Reações Adversas Relacionados a Medicamentos; } \\
\text { Ensino Fundamental e Médio; Estado Pré-Diabético; Estudantes; Estudos Transversais; } \\
\text { Federalismo; Hospitalização; Incidência; Indicadores básicos de saúde; Monitoramento; } \\
\text { Mortalidade Infantil; Periodontite; Política de Saúde; Redes Comunitárias; Saúde; } \\
\text { Segurança do paciente; Segurança do Sangue; Serviços de Saúde; Serviços Médicos de } \\
\text { Emergência; Sistemas de Informação; Sono; Trabalho; Transportes; Uso de } \\
\text { medicamentos; Violência. }\end{array}$ & 2 \\
\hline $\begin{array}{l}\text { Abuso de maconha; Acesso aos Serviços de Saúde; Acidentes; Acidentes de trabalho; } \\
\text { Actigrafia; Adesão à medicação; Administração hospitalar; Admissão do paciente; } \\
\text { Adolescente; Aids; Aleitamento materno; Alfabetização; Antagonistas Colinérgicos; } \\
\text { Antropometria; Assistência Ambulatorial; Assistência Odontológica; Associação; } \\
\text { Atenção à Saúde; Atividade Motora; Atividades cotidianas; Autonomia pessoal; } \\
\text { Barreiras; Capacitação em Serviço; Capacitação profissional; Carga de Trabalho; } \\
\text { Casamento; Causas externas; Centros de Especialidades Odontológicas; Circunferência } \\
\text { abdominal; Classificação Internacional de Doenças; Comportamentos Relacionados } \\
\text { com a Saúde; consciência; Crescimento; Cuidado Pré-Natal; cultura organizacional; } \\
\text { Dente Decíduo; Depressão; Dermatomicoses; Desapego Psicológico; Diagnóstico da } \\
\text { Situação de Saúde; Direito à Saúde; Disparidades nos Níveis de Saúde; Doenças } \\
\text { transmissíveis; Doenças transmissíveis emergentes; Educação; Educação Superior; } \\
\text { Eficiência; Enfermagem; Enfermagem em Emergência; Ensino; Epidemiologia; Equipe } \\
\text { de enfermagem; Ergologia; Estado nutricional; Estilo de Vida; Estilo de Vida Saudável; } \\
\text { Estresse; Estresse Psicológico; Estudos de coortes; Estudos transversais; Exposição; } \\
\text { Farmacoepidemiologia; Fenomenologia; Frutas; Gestantes; Gestão da Segurança; } \\
\text { Grupo com ancestrais do continente africano; Grupos de Risco; Grupos Populacionais; } \\
\text { Hábitos; Hospitais de Ensino; Imagem Corporal; Índice de Massa Corporal; Índios Sul- } \\
\text { Americanos; Infecçães por HIV; Instituição de longa permanência para idosos; } \\
\text { Instituições Acadêmicas; Inventário de Beck II; Letramento em Saúde; Má oclusão; } \\
\text { Manganês; Materiais Biocompatíveis; Maternagem; Maurice Merleau-Ponty; } \\
\text { Medicamentos Essenciais e Tecnologias em Saúde; Medição de Risco; Medicina de } \\
\text { Emergência; Medicina Preventiva; Micropolítica; Migração humana; Ministério Público; } \\
\text { Morbidade; Motocicletas; Mudança na situação conjugal; Mulheres; Necessidades e } \\
\text { demandas de Serviços de Saúde; Newest Vital Sign; NVS; Obesidade Abdominal; } \\
\text { Organização e administração; Pé diabético; Percepção; Percepção de peso; Período } \\
\text { Pós-Parto; Pessoa de Meia-idade; Pessoa em situaça de rua; Pessoas com deficiência; }\end{array}$ & 1 \\
\hline
\end{tabular}




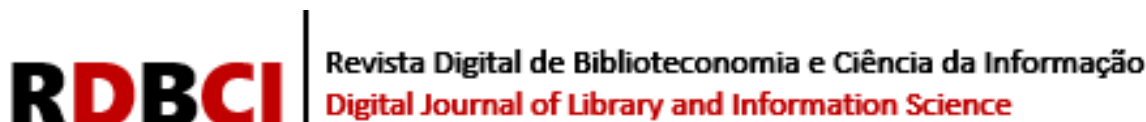

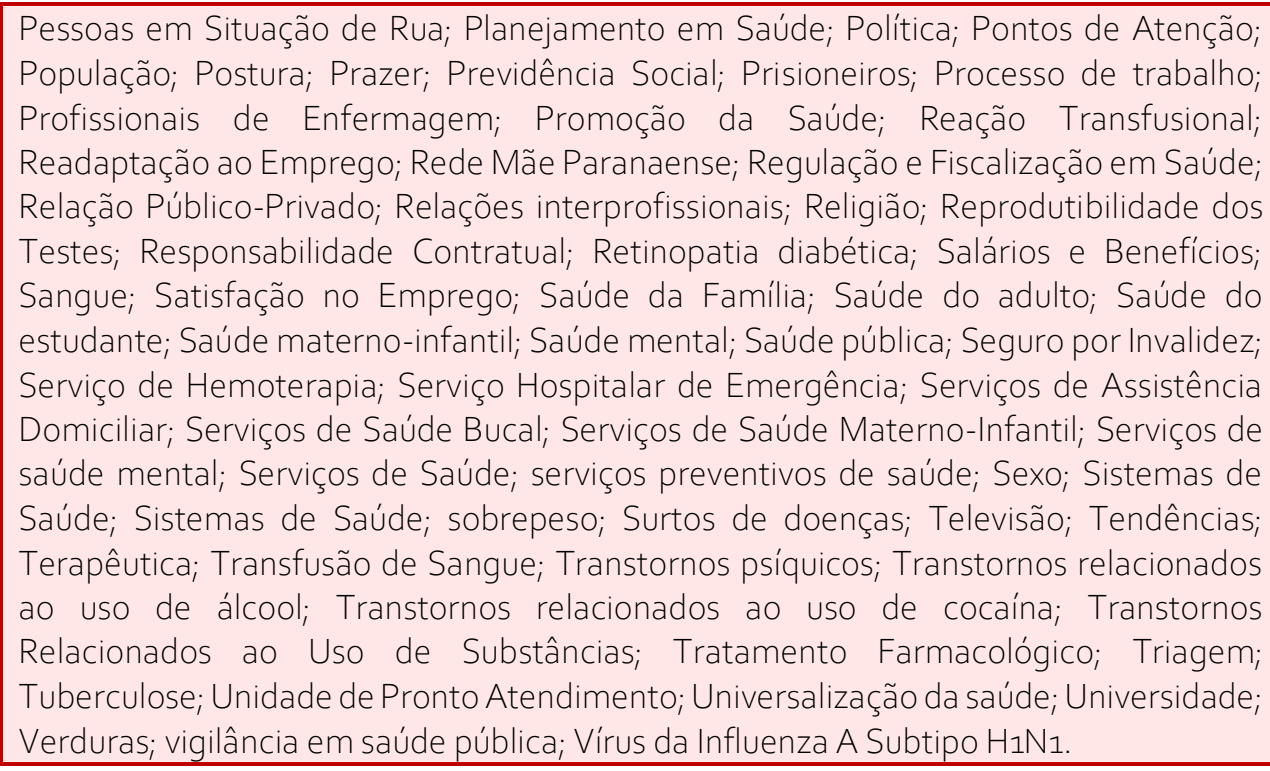

Fonte: Elaborado pelas autoras (2021)

Considerando o período analisado e os métodos utilizados para se obter o resultado, identificou-se como elementos de maior representatividade, dentre as temáticas, as palavraschave:

1) Atenção Primária à Saúde (APS);

2) Docentes;

3) Diabetes Mellitus;

4) Sistema Único de Saúde.

Logo, será apresentado o resultado das análises das palavras-chave mais empregadas. Assim sendo, compreende-se que tratam-se de temáticas que representam a informação em saúde do PPGSC/UEL, considerando as 91 dissertações desenvolvidas e aprovadas pelo Programa dentro do período analisado.

1) Atenção primária à saúde: No que tange à temática mais recorrente no estudo em tela, a Atenção Primária à Saúde (APS), constitui-se, “[...] como um filtro capaz de organizar o fluxo dos serviços nas redes de saúde, dos mais simples aos mais complexos." (ATENÇÃO..., 2020). Diante disso, de acordo com o Ministério da Saúde (MS), a APS é o primeiro nível de atenção em saúde e se caracteriza por um conjunto de ações de saúde, no contexto individual e coletivo, que tem como objetivo desenvolver uma atenção integral que impacte positivamente na situação de saúde das coletividades, que abrange a promoção e a proteção da saúde, a prevenção de agravos, o diagnóstico, o tratamento, a reabilitação, a redução de danos e a manutenção da saúde com o propósito de desenvolver uma atenção integral que impacte positivamente na situação de saúde das coletividades. (Brasil, 2020a). Há diversas estratégias, relacionadas à APS, no Brasil: serviços como consultas, exames, vacinas entre outros para as comunidades/usuários, por meio das redes de serviços de saúde. Além de serviços, de apoio à gestores na tomada de decisões, com o objetivo de direcionar (do conhecer) à população das ações da APS, entre outros programas, de ações e estratégias no âmbito governamental.

Dentre os trabalhos analisados, os temas desenvolvidos com o enfoque temática APS, estão as dissertações com os títulos: "Risco de ulceração em pés de portadores de diabetes mellitus em Londrina, Paraná: caracterização do cuidado na atenção básica, prevalência e fatores associados" (BORTOLETTO, 2010). "Características antropométricas de crianças de 6 a 23 meses de idade e fatores associados a desvios nutricionais" (SILVA, 2012); "Avaliação da 


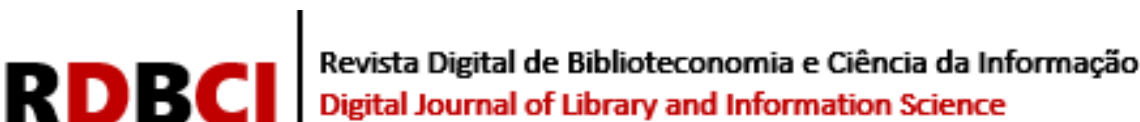

atenção às pessoas com hipertensão e ou diabetes no município de Cambé - PR. 2014" (RADIGONDA, 2014); "A Territorialização e o Planejamento em uma Unidade Saúde da Família”.(MORGADO, 2017); Cultura de segurança do paciente na atenção primária à saúde, Londrina, Paraná (MACEDO, 2018). Núcleos Ampliados de Saúde da Família e Atenção Básica e as Práticas Colaborativas para o cuidado integral (MAZZA, 2020).

Nesse contexto, percebeu-se que dentre os trabalhos identificados foram desenvolvidas temáticas interrelacionadas às questões inerentes à Diabetes mellitus, tais como o diagnóstico e tratamento, o uso de medicamentos, fatores de risco, doenças associadas, e sobretudo as consequências da doença. Também foram abordados temas acerca de acidentes com motocicletas, nutrição e práticas gerenciais da atenção primária à saúde. Observou-se ainda que a APS está presente quase que constantemente nos trabalhos, embora nem sempre tenha se utilizado o termo específico nas palavras-chave.

A APS é conhecida como "a 'porta de entrada' dos usuários nos sistemas de saúde, pois, tem como intento orientar sobre a prevenção de doenças, solucionar os possíveis casos de agravos e direcionar os mais graves para níveis de atendimento superiores em complexidade." (ATENÇÃO..., 2020). Nesse contexto, destacam-se os princípios do SUS, agregados a APS, descritos pelo Ministério da Saúde que são: Universalização: a saúde é um direito de cidadania de todas as pessoas; Equidade: o objetivo é diminuir desigualdades; Integralidade: considera as pessoas como um todo, no atendimento das necessidades de saúde e qualidade de vida dos indivíduos. (BRASIL, 2020b).

Fundamentando-se em Werneck (2020), entende-se que as abordagens da Saúde Coletiva e mais especificamente da APS, contribuem para mudanças, novas oportunidades e pesquisa e ajustes aos cursos de pós-graduação, com perspectivas no campo das emergências em saúde pública, de forma mais crítica a avaliação do impacto e das intervenções populacionais.

2) Diabetes Mellitus: Como visto no tópico anterior, nos trabalhos analisados houve grande relação entre as palavras-chave diabetes e APS. Também foram abordadas outras temáticas, como a assistência ao paciente; aos fatores de risco associados; os sintomas para os cuidados e prevenção; a relação com outras doenças, como por exemplo as doenças vasculares; o uso de medicamentos e a ulceração em pés e fatores relacionados a nutrição. Nesse âmbito, trabalhos foram desenvolvidos com os seguintes temas: Retinopatia diabética em indivíduos com diabetes e pré-diabetes no município de Cambé-PR. (OLIVEIRA, 2016); Fatores de risco para a incidência de diabetes mellitus e pré-diabetes em indivíduos de 40 anos ou mais: um estudo de corte. (ADATIHARA, 2018).

O Diabetes Mellitus, é considerado um problema de saúde pública em todo o mundo. É uma das doenças crônicas de maior impacto nos gastos com saúde, pois quando mal controlado, traz complicações macro e microvasculares graves, que oneram os serviços de saúde. Dados da OMS têm apontado para um aumento grande da prevalência da doença no cenário mundial. Estudos revelam o crescimento da doença, em países considerados desenvolvidos e em desenvolvimento, fato esse que ocorre devido ao envelhecimento da população e aos hábitos de vida sedentários. Nesse contexto, importante salientar e alertar que o Brasil aparece como um dos países com prevalência da doença. Consideram-se fatores de risco, tais como os hábitos alimentares e o estilo de vida estão associados à prevalência de diabetes na população.

3) Docentes: Identifica-se dentre as mais recorrentes a palavra-chave docentes. Tendo em vista que foram estudadas, principalmente, questões referentes à saúde física e psicológica dos docentes enfoques que envolvem a saúde pública. Outras temáticas envolveram também problemas nutricionais dos docentes; o processo de capacitação; a satisfação profissional dos

RDBCl: Rev. Dig. Bibliotec e Ci. Info. / RDBCl: Dig. J. of Lib. and Info. Sci. | Campinas, SP | v.19| e021014 | 2021 


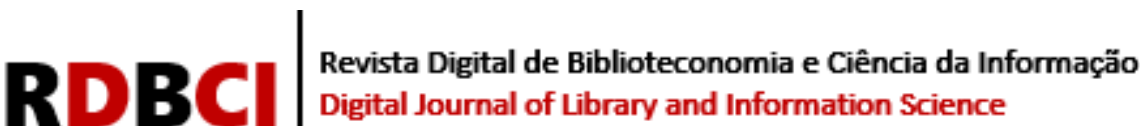

professores e as manifestações de violência escolar contra professores, bem como os fatores associados a esse cenário.

Destaca-se no período analisado, pertinente a palavra-chave "Docentes", que os trabalhos estão relacionados a um projeto de pesquisa desenvolvido pelo Programa de PósGraduação em Saúde Coletiva da Universidade Estadual de Londrina (UEL) - Projeto de Monitoramento do Estilo de vida, da Saúde e do Trabalho de Educadores, intitulado "Saúde, estilo de vida e trabalho de professores da Rede Estadual de Londrina" (PRÓ-Mestre) ${ }^{1}$, que teve por objetivo analisar as relações do estado de saúde e do estilo de vida dos professores da rede estadual de Ensino e relacioná-los com aspectos do processo de trabalho. O processo de trabalho docente pode ser marcado por uma expressiva carga horária em sala de aula, excesso de tarefas burocráticas, falta de autonomia e infraestrutura no ambiente escolar, além das frequentes relações conflitantes com alunos e seus familiares. Infelizmente, essas condições de trabalho têm implicações na saúde física e mental dos professores e, por conseguinte, interferem negativamente na sua realização profissional e na capacidade para manter-se ativos e com o mesmo rendimento ao longo da carreira. Portanto, o PRÓ-Mestre propõe uma análise compreensiva dos diversos fatores que podem explicar como e com que intensidade certos problemas de saúde comprometem a capacidade para o trabalho e a satisfação com o trabalho em professores.

No período em que o projeto foi desenvolvido destacam-se que entre os temas de pesquisa, estão os títulos das dissertações: "Violência escolar contra professores da Rede Estadual de Ensino de Londrina: caracterização e fatores associados." (NESELLO, 2014); "Condutas alimentares e fatores associados em professores da Rede Estadual de Ensino de Londrina-PR". (DIAS, 2014); Satisfação no trabalho e absenteísmo entre professores da rede estadual de ensino básico de Londrina. (LEVORATO, 2016); Dor em professores da educação básica: associação com atividade física e tempo vendo televisão. (SANTOS, 2020).

4) Sistema Único de Saúde: O Sistema Único de Saúde (SUS) brasileiro é um dos maiores do mundo com acesso universal a serviços e ações de saúde. Este está assegurado na Constituição Brasileira como condição de cidadania, fruto do Movimento da Reforma Sanitária. O SUS distingue o desenvolvimento social do Brasil atual e dignifica a todas e todos os brasileiros. (OPAS, 2018, p.4).

Entre os temas desenvolvidos cita-se: Atuação do Ministério Público Estadual de Londrina na área da saúde pública: análise das demandas e atividades (TAVARES, 2010), considera-se a saúde como direito de todos e suas ações e serviços caracteriza-se como relevância pública, destaca-se a importância do Ministério Público junto ao Sistema Único de Saúde, buscando ações que almejam o direito à saúde; Não adesão ao tratamento medicamentoso contínuo e fatores associados: estudo de base populacional. (REMONDI, 2012); Governança das Ações e Serviços de Média Complexidade em uma Região de Saúde (FERRAZ, 2018); SUS para todos, para pobres ou para ninguém? A visão de estudantes de Educação Física de três universidades públicas do Paraná (PIMENTEL, 2020).

A partir das análises apresentadas, entende-se que o campo da Saúde Coletiva envolve uma vasta gama de possibilidades temáticas em prol da saúde, que contemplam além de debates, a produção do conhecimento científico em âmbito social e na esfera coletiva. Dentre as temáticas identificadas pautam-se questões alusivas ao gerenciamento dos serviços, desempenho dos profissionais de saúde, à acessibilidade dos serviços de saúde pelos indivíduos que dele necessitam, as equipes de assistência e os medicamentos disponibilizados para a população. Nesse sentido, considerando o contexto das contribuições para a saúde pública brasileira, oriundas da Reforma Sanitária Brasileira, evidencia-se o processo de implantação e

\footnotetext{
${ }^{1}$ Disponível em: http://www.uel.br/projetos/promestre/
} 


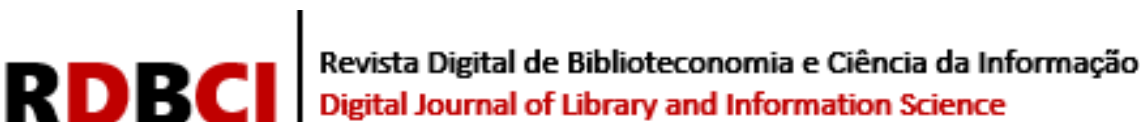

implementação do SUS - que tem como finalidade assegurar os direitos do cidadão brasileiro à saúde, à previdência, e à assistência social.

Sendo assim, foram analisadas e contextualizadas as palavras-chave de maior representatividade na saúde coletiva, considerando especificamente o PPGSC/UEL. Importa mencionar, que as demais palavras-chave identificadas, que não foram exploradas nesse artigo, são importantes abordagens representativas, uma vez que reproduzem as temáticas desenvolvidas pelo campo e refletem em contribuições para as demandas pertinentes a saúde da população brasileira. Outrossim entende-se que, dentre as inúmeras pesquisas científicas realizadas no campo da Saúde Coletiva, ratificam-se a relação teoria-prática do campo. Isto posto, evidencia-se, que a Saúde Coletiva tem como preocupação a saúde pública - a saúde dos indivíduos, dos grupos étnicos, das classes sociais e das populações. Nesse sentido, acredita-se que a natureza interdisciplinar do campo tem possibilitado inovações relevantes, frente aos novos desafios da saúde no país. Ressalta-se que pesquisas na pós-graduação em Saúde Coletiva, por meio de seus vários enfoques, podem ser norteadores de políticas públicas e de várias demandas sociais.

Enfatiza-se a importância da organização e representação da informação, com relação à atribuição de palavras-chave em pesquisas científicas. Nesse contexto, reforça-se a premissa que dentre as formas de representação da informação, a palavra-chave representa um documento de forma condensada e apresenta-se de forma profícua elementos representativos do conteúdo dos trabalhos científicos desenvolvidos, ou seja, uma forma de comunicar o assunto do documento. Diante do exposto, entende-se que valorizar a representação da informação, o fator comunicacional, significa garantir suas diversas facetas na relação com o registro informacional. (ALBUQUERQUE; GAUDÊNCIO; SANTOS, 2019). Em consonância com Novellino (1998, p. 138), ressalta-se que "a ação de transferência da informação depende de linguagens formalizadas que facilitem a comunicação entre produtores, organizadores e usuários da informação".

Cabe pontuar, que enquanto, contribuição da Ciência da Informação, considerando o eixo da representação da informação, as palavras-chave são ferramentas que auxiliam no processo de tomada de decisão do leitor, no que diz respeito ao acesso ao texto na íntegra. Logo, parafraseando Garcia, Gattaz e Gattaz (2019), no que se refere aos benefícios alcançados por meio da visibilidade, da apreciação e legitimação dos trabalhos científicos, dos fatores de reconhecimento de uma pesquisa, destaca-se o papel das palavras-chave resumindo o tema e as principais ideias de um documento científico.

Tais termos, são utilizados por pesquisadores e estudiosos para identificar o conteúdo semântico de determinado assunto, refletindo o pensamento dos autores nos mais diversos trabalhos científicos, como também, representam o título, o resumo, o conteúdo do documento, ou seja, a temática que é tratada no documento. Para que essa busca obtenha êxito, é necessário que tais documentos estejam organizados. Nessa direção, importa mencionar que a organização da informação concretiza-se por meio de sua representação, bem como do processo cognitivo viabilizando que um documento seja descrito, identificado, individualizado e organizado sistematicamente em uma coleção, seja ela em meio físico ou virtual.

É sabido a importância das palavras-chave na representação da informação, como fator de identificação, comunicação, transmissão e a compreensão da informação, já que possibilita a interação entre documento e o usuário e, sobretudo, quando na representação temática que torna o processo de recuperação da informação possível e compreende-se, de forma precisa e pertinente.

Nessa linha de raciocínio, a informação é essencial à realização de qualquer tarefa, está presente em todas as atividades do ser humano e, consequentemente, deve ser socializada: 


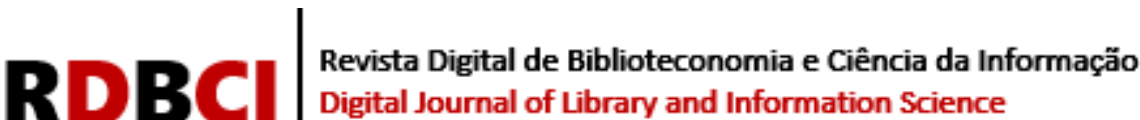

\begin{abstract}
Desse modo, o foco passa a ser a busca por metodologias, instrumentos e estratégias que possibilitem que as etapas de identificação, acesso, recuperação e disseminação de informação formem, juntas, um espaço de transformação, recriação e/ou criação de nova informação. Essa abordagem teórica vem sendo construída no âmbito de uma especialidade emergente da Ciência da Informação, denominada "Socialização da Informação". Aqui, mais uma vez, o caminho a ser trilhado pede participação e parceria entre os atores, entre produtores, intermediários e usuários de informação, especialmente nos limites onde os espaços se diferenciam, na fronteira que separa a evidência científica...[...]. (GUIMAR ÃES, 2010, p. 56).
\end{abstract}

Parafraseando Gomes (2018), a saúde coletiva, enquanto campo científico oriundo de um movimento social para sua compreensão em termos de condições e necessidades de saúde, se compromete ao estudo dessas condições como propostas de políticas públicas, bem como a disseminação na sociedade de conhecimentos que possibilitem alterar suas condições de saúde. Nesse sentido, a parceria da saúde coletiva e o campo da Ciência da Informação está na geração de serviços e produtos que, possam auxiliar na obtenção das informações com intuito de análise e estudo.

Valendo-se dos conceitos que sustentam as palavras-chave empregadas, torna-se possível constatar que o campo da Saúde Coletiva prioriza a promoção, prevenção e proteção da saúde, sob a ótica da administração, gestão e planejamento de políticas, serviços e programas e articula o campo com saberes e práticas nas diferentes esferas: sociocultural, política, educacional, ambiental, organizacional, econômica e biológica e, principalmente, informacional, incorporando propostas inovadoras no contexto nacional.

\section{CONSIDERAÇÕES FINAIS}

A Saúde Coletiva trata-se de um campo científico que produz conhecimentos acerca do objeto saúde, com vistas à promoção e a prevenção da saúde em âmbito coletivo. Nesse sentido, compreende-se que inserem-se pesquisas científicas, de questões epidemiológicas, socioeconômicas, ambientais e demográficas e culturais.

Dentre os enfoques contemplados pelo campo da Saúde Coletiva, especialmente pelo PPGSC da UEL, observou-se a diversidade de assuntos pesquisados a diversidade de assuntos pesquisados com vistas ao SUS, entre outros temas encontrados nos trabalhos científicos, inseridos no contexto brasileiro. Contudo, constatou-se que algumas temáticas não foram identificadas dentre os produtos científicos. Tais como: a inclusão social de pessoas com deficiência, e suas necessidades enquanto assistência à saúde bucal, problemas de saúde relacionados ao diabetes e doenças cardiovasculares, entre outros aspectos pertinentes as necessidades e acessibilidade de informações em saúde para as pessoas com deficiência.

Por intermédio de estudos da área da Ciência da Informação, especificamente, da representação temática da informação, foram identificadas as palavras-chave das dissertações e, sobretudo as palavras-chave mais recorrentes. Salienta-se que os estudos envolvendo as temáticas sejam na Saúde Coletiva e Saúde Pública, não se deve e tão pouco se esgotar. Nesse sentido, ratifica-se a importância e necessidade da ciência para a sociedade a partir de visões das várias áreas do conhecimento, que foram contempladas a partir dos títulos de algumas dissertações.

O uso de linguagem, o uso de delimitadores dos termos torna-se um elemento de significativa importância e a escolha das palavras-chave deve apresentar-se de forma compreensível e com, se possível, a devida conexão do produto científico desenvolvido. As palavras-chave são decorrentes da linguagem natural do autor, retiradas do próprio texto, 


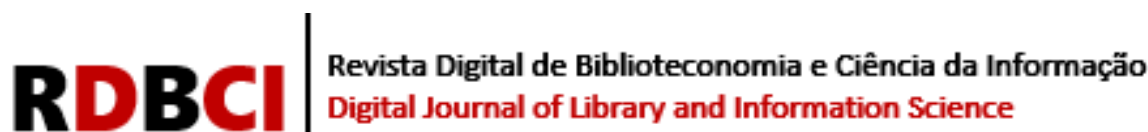

enquanto os descritores são termos previamente selecionados e validados por especialistas na área. Entretanto, cabe ressaltar que os dois termos estão ligados à ideia de representar, de identificar as informações mais relevantes de um documento.

A Ciência da Informação, enquanto ciência social aplicada, realiza estudos em várias áreas do conhecimento. O campo da Saúde Coletiva, possibilita que a Ciência Informação identifique estudos relacionadas à saúde pública brasileira, desenvolvidas por uma instituição de ensino público, no âmbito da Pós-Graduação. Assim sendo, sem que se esgotem outras propostas de pesquisa, evidencia-se, nesse artigo, o relevante papel da representação temática, com vistas a recuperação e a socialização da informação científica e em especial, à da área pesquisada.

\section{CRediT}

RECONHECIMENTOS: Não aplicável.

FINANCIAMENTO: Não aplicável.

CONFLITOS DE INTERESSES: Os autores certificam que não têm qualquer interesse comercial ou associativo que represente um conflito de interesses em relação ao manuscrito.

APROVAÇÃO ÉTICA: Não aplicável.

DISPONIBILIDADE DE DADOS E MATERIAL: Não se aplica.

CONTRIBUIÇÕES DOS AUTORES: - Conceituação, Curadoria de Dados, Análise Formal, Aquisição de

Financiamento, Investigação, Metodologia, Administração de Projetos, Recursos, Software, Supervisão, Validação, Visualização, Redação - rascunho original: LAGE, S.R.M.; ALMEIDA, P.P. de; LUNARDELLI, R.S.A.; Redação revisão \& edição: LAGE, S.R.M.; ALMEIDA, P.P. de; LUNARDELLI, R.S.A.

\section{REFERÊNCIAS}

ADATIHARA, Thiago Akira. Fatores de risco para a incidência de diabetes mellitus e prédiabetes em indivíduos de 40 anos ou mais: um estudo de coorte. $2018.148 \mathrm{f}$.

Dissertação (Mestrado em Saúde Coletiva) - Universidade Estadual de Londrina, Centro de Ciências da Saúde, Londrina, 2018. Disponível em:

http://www.uel.br/pos/saudecoletiva/portal/pages/arquivos/Mestrado/diss/Turma2016/Dissertação - Thiago Akira Adatihara - Mestrado em Saúde Coletiva.pdf . Acesso em: 2 abr. 2021.

ALBUQUERQUE, Maria Elizabeth Baltar Carneiro; GAUDÊNCIO, Sale Mário; SANTOS, Raimunda Fernanda dos. Reflexões teóricas em representação da informação. In:

ALBUQUERQUE, Maria Elizabeth Baltar Carneiro; MARTINS, Gracy Kelli; MOTA, Denysson Axel Ribeiro (org.). Organização e representação da informação e do conhecimento: intersecções teórico-sociais. João Pessoa: UFPB, 2019. p. 13-24.

ARAÚJO JÚNIOR, Rogério Henrique de. Precisão no processo de busca e recuperação da informação. Brasília: Thesaurus, 2007.

ATENÇÃO básica. In: Fundação Oswaldo Cruz (FIOCRUZ). SUS de A a Z. Rio de Janeiro: FIOCRUZ. Disponível em: https://pensesus.fiocruz.br/atencao-basica. Acesso em: 11 jul. 2020.

BARRETO, Aldo de Albuquerque. Uma quase história da ciência da informação.

DataGramaZero: Revista de Ciência da Informação, Rio de Janeiro, v. 9, n. 2, p. 1-15, abr. 


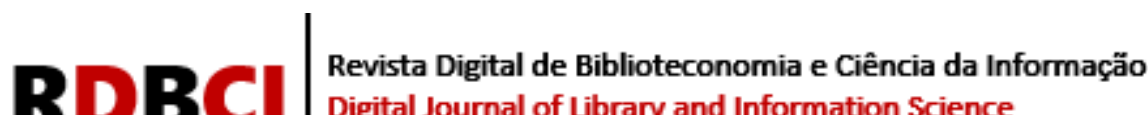 \\ Digital Journal of Library and Information Science}

2008. Disponível em: http://eprints.rclis.org/17637/1/DataGramaZero - Revista de Ciência da Informação - Artigo 01_Aldo.pdf. Acesso em: 8 abr. 2021.

BARRETO, Maurício L. A pesquisa em saúde coletiva no Brasil. Cadernos de Saúde Pública, Rio de Janeiro, v. 19, n. 2, p. 354-355, mar./abr. 2003. Disponível em: http://www.scielo.br/pdf/csp/v19n2/15400.pdf. Acesso em: 24 fev. 2020.

BELKIN, Nicholas J.; ROBERTSON, Stephen E. Information science and the phenomena of information. Journal of the American Society for Information Science, v. 27, n. 4, p. 197204, 1976.

BORBA, Diego dos Santos; VAN DER LAAN, Regina Helena; CHINI, Bernadete Ros. Palavras-chave: convergências e diferenciações entre a linguagem natural e a terminologia. Perspectivas em Ciência da Informação, Belo Horizonte, v. 17, n. 2, p. 26-36, jun. 2012. Disponível em: http://www.scielo.br/scielo.php?script=sci arttext\&pid=S141399362012000200003\&lng=pt\&nrm=iso. Acesso em 29 jun. 2020.

BORTOLETTO, Maira Sayuri Sakay. Risco de ulceração em pés de portadores de diabetes mellitus em Londrina, Paraná: caracterização do cuidado na atenção básica, prevalência e fatores associados. 2010. 131f. Dissertação (Mestrado em Saúde Coletiva) - Universidade Estadual de Londrina, Centro de Ciências da Saúde, Londrina, 2010. Disponível em: http://www.uel.br/pos/saudecoletiva/Mestrado/res/100.html. Acesso em: 2 abr. 2021.

BRÄSCHER, Marisa; CAFÉ, Ligia Maria Arruda. Organização da informação ou organização do conhecimento? In: ENCONTRO NACIONAL DE PESQUISA EM CIÊNCIA DA INFORMAÇÃO - ENANCIB, 9., 2008, São Paulo. Anais [...] São Paulo: ANCIB, 2008. p. 114. Disponível em:

http://repositorios.questoesemrede.uff.br/repositorios/handle/123456789/809. Acesso em: 20 fev. 2020.

BRASIL. Ministério da Saúde. O que é Atenção Primária? Disponível em: https://aps.saude.gov.br/smp/smpoquee. Acesso em: 16 jul. 2020a.

BRASIL. Ministério da Saúde. Princípios do SUS. Disponível em: https://antigo.saude.gov.br/sistema-unico-de-saude/principios-do-sus . Acesso em: 15 jul. 2020 b.

CAFÉ, Ligia Maria Arruda; SALES, Rodrigo de. Organização da informação: conceitos básicos e breve fundamentação teórica. In: ROBREDO, Jaime; BRÄSCHER, Marisa. (org.). Passeios no bosque da informação: estudos sobre representação e organização da informação e do conhecimento. Brasília, DF: IBICT, 2010. p. 115-129. Disponível em: https://www2.senado.leg.br/bdsf/handle/id/189812. Acesso em: 1 fev. 2020.

CINTRA, Anna Maria Marques; TÁLAMO, Maria de Fátima Gonçalves Moreira; LARA, Marilda Lopes Ginez de; KOBASHI, Nair Yumiko. Para entender as linguagens documentárias. 2. ed. São Paulo: Polis, 2002.

DIAS, Ana Luísa. Condutas alimentares e fatores associados em professores da Rede Estadual de Ensino de Londrina-PR. 2014. 165f. Dissertação (Mestrado em Saúde 


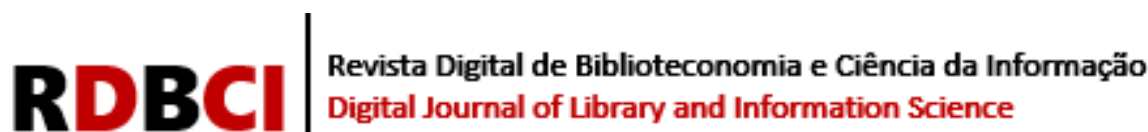

Coletiva) - Universidade Estadual de Londrina, Centro de Ciências da Saúde, Londrina, 2014. Disponível em:

http://www.uel.br/pos/saudecoletiva/portal/pages/dissertacoesteses/dissertacoes/dissertacoesa-partir-de-2012.php. Acesso em: 2 abr. 2021.

DIAS, Eduardo Wense; NAVES, Madalena Lopes. Análise de assunto: teoria e prática. 2. ed. Brasília: Thesaurus, 2013.

FERRAZ, Edinalva de Moura. Governança das ações e serviços de média complexidade em uma região de saúde. 2018. 79 f. Dissertação (Mestrado em Saúde Coletiva) Universidade Estadual de Londrina, Centro de Ciências da Saúde, Londrina, 2018. Disponível em:

http://www.uel.br/pos/saudecoletiva/portal/pages/dissertacoesteses/dissertacoes/dissertacoesa-partir-de-2012.php. Acesso em: 2 abr. 2021.

FUJITA, Mariângela Spotti Lopes. A representação documentária de artigos científicos em educação especial: orientação aos autores para determinação de palavras chaves. Revista Brasileira de Educação Especial, Marília, v. 10, n. 3, p. 257-272, 2004. Disponível em: http://educa.fcc.org.br/scielo.php?script $=$ sci arttext\&pid $=$ S141365382004000300002\&lng=pt\&nrm=iso. Acesso em: 12 jul. 2020.

GARCIA, Débora Cristina Ferreira; GATTAZ, Cristiane Chaves; GATTAZ, Nilce Chaves. A relevância do título, do resumo e de palavras-chave para a escrita de artigos científicos.

Revista de Administração Contemporânea, Maringá, PR, v. 23, n. 3, maio/junho, 2019. Disponível em: https://www.scielo.br/pdf/rac/v23n3/1982-7849-rac-2019190178.pdf. Acesso em: 30 jun. 2020.

GIL, Antonio Carlos. Como elaborar projetos de pesquisa. 6. ed. São Paulo: Atlas, 2017.

GIL-LEIVA, Isidoro; ALONSO-ARROYO, Adolfo. La relación entre las palabras clave aportadas por los autores de artículos de revista y su indización en las bases de datos ISOC, IME e ICYT. Revista española de Documentación Científica, Madrid, v. 28, n. 1, p. 62-79, 2005. Disponível em: http://redc.revistas.csic.es/index.php/redc/article/view/165/219. Acesso em: 28 out. 2018.

GOMES, Henriette Ferreira. Protagonismo socioinformacional na saúde coletiva. Informação em Pauta, Fortaleza, v. 3, núm. esp., p. 47-61, nov. 2018. Disponível em:

https://dialnet.unirioja.es/servlet/articulo?codigo=6699059. Acesso em: 6 mar. 2021.

GUIMARÃES Maria Cristina Soares. Uma geografia para a ciência faz diferença: um apelo da Saúde Pública. Cadernos de Saúde Pública, Rio de Janeiro, v. 26, n. 1, p. 50-58, jan. 2010. Disponível em: http://www.scielo.br/scielo.php?script $=$ sci arttext\&pid=S0102311X2010000100006\&lng=pt\&nrm=iso. Acesso em: 6 dez. 2020.

GUIMARÃES, Cristian. Produção operária italiana e movimento sanitário brasileiro: contribuições para pensar a noção de coletivo. Saúde em debate, Rio de Janeiro, v. 43, n. 5, p. 113-125, 2019. Disponível em:

http://www.scielo.br/scielo.php?script=sci arttext\&pid=S010311042019001000113\&lng=en\&nrm=iso. Acesso em: 6 mar. 2021. 


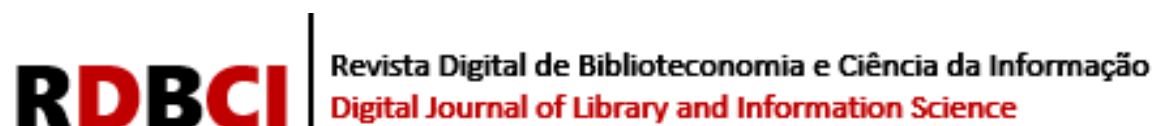

HARTLEY, James; KOSTOFF, Ronald N. How useful are 'key words' in scientific journals? Journal of Information Science, Cambridge, v. 29, n. 5, p. 433-438, 2003. Disponível em: https://journals-sagepubcom.ez78.periodicos.capes.gov.br/doi/pdf/10.1177/01655515030295008. Acesso em: 17 jul. 2020.

LEVORATO, Adrieli de Fátima Massaro. Satisfação no trabalho e absenteísmo entre professores da rede estadual de ensino básico de Londrina. 2016. 142 p. Dissertação (Mestrado em Saúde Coletiva) - Universidade Estadual de Londrina, Centro de Ciências da Saúde, Londrina, 2016. Disponível em:

http://www.uel.br/pos/saudecoletiva/portal/pages/dissertacoesteses/dissertacoes/dissertacoesa-partir-de-2012.php. Acesso em: 2 abr. 2021.

LIMA, Nísia Trindade; SANTANA, José Paranaguá de. Apresentação. In: LIMA, Nísia Trindade; SANTANA, José Paranaguá de. Saúde coletiva como compromisso: a trajetória da Abrasco. Rio de Janeiro: Fiocruz: Abrasco, 2006. p. 9-15.

LOYOLA, Maria Andréa. O lugar das ciências sociais na saúde coletiva. Saúde e Sociedade, São Paulo, v. 21, n. 1, p. 9-14, jan./ mar., 2012. Disponível em: http://www.scielo.br/scielo.php?script $=$ sci arttext\&pid=S010412902012000100002\&lng=en\&nrm=iso. Acesso em: 18 fev. 2020.

MACEDO, Lilian Louzada. Cultura de segurança do paciente na atenção primária à saúde, Londrina, Paraná. 2018. 110f. Dissertação (Mestrado em Saúde Coletiva) -

Universidade Estadual de Londrina, Centro de Ciências da Saúde, Londrina, 2018. Disponível em: http://www.bibliotecadigital.uel.br/document/?code=vtls000217660. Acesso em: 2 abr. 2021.

MAZZA, Daiene Aparecida Alves. Núcleos ampliados de saúde da família e atenção básica e as práticas colaborativas para o cuidado integral. 2020. 159f. Dissertação (Mestrado em Saúde Coletiva) - Universidade Estadual de Londrina, Centro de Ciências da Saúde, Programa de Pós-Graduação em Saúde Coletiva, 2020. Disponível em: http://www.bibliotecadigital.uel.br/document/?code=vtls000231203. Acesso em: 2 abr. 2021.

MIGUÉIS, Ana et al. A importância das palavras-chave dos artigos científicos da área das Ciências Farmacêuticas, depositados no Estudo Geral: estudo comparativo com os termos atribuídos na MEDLINE. InCID: Revista de Ciência da Informação e Documentação, Ribeirão Preto, v. 4, n. 2, p. 112-125, dez. 2013. Disponível em: https://www.revistas.usp.br/incid/article/view/69284. Acesso em: 16 jun. 2020.

MORGADO, Ana Paula Correa Pardal. A territorialização e o planejamento em uma unidade saúde da família. 2017. 120f. Dissertação (Mestrado em Saúde Coletiva) Universidade Estadual de Londrina, Centro de Ciências da Saúde, Londrina, 2017. Disponível em: http://www.bibliotecadigital.uel.br/document/?code=vtls000211032. Acesso em: 2 abr. 2021.

NESELLO, Francine. Violência escolar contra professores da Rede Estadual de Ensino de Londrina: caracterização e fatores associados. 2014. 156f. Dissertação (Mestrado em Saúde 


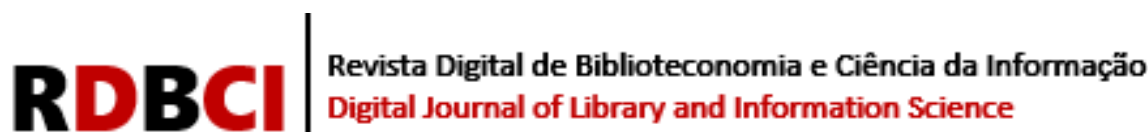

Coletiva) - Universidade Estadual de Londrina, Centro de Ciências da Saúde, Londrina, 2014. Disponível em:

http://www.uel.br/pos/saudecoletiva/portal/pages/dissertacoesteses/dissertacoes/dissertacoesa-partir-de-2012.php. Acesso em: 2 abr. 2021.

NOVAES, Hillegonda Maria Dutilh et al. Pós-Graduação senso estrito em Saúde Coletiva e o Sistema Único de Saúde. Ciência \& Saúde Coletiva, Rio de Janeiro, v. 23, n. 6, p. 20172025, jun. 2018. Disponível em: http://www.scielo.br/scielo.php?script=sci arttext\&pid=S1413-81232018000602017\&lng=en\&nrm=iso. Acesso em: 28 fev. 2021.

NOVELLINO, Maria Salet Ferreira. A linguagem como meio de representação ou de comunicação da informação. Perspectivas em Ciência da Informação, Belo Horizonte, v. 3, n. 2, p. 137-146, jul./dez. 1998. Disponível em:

http://portaldeperiodicos.eci.ufmg.br/index.php/pci/article/view/602. Acesso em: 1 jun. 2019.

NOVELLINO, Maria Salet Ferreira. Instrumentos e metodologias de representação da informação. Informação e Informação, Londrina, v. 1, n. 2, p. 37-45, jul./dez. 1996. Disponível em: http://www.uel.br/revistas/uel/index.php/informacao/article/view/1603/1358. Acesso em: 1 jun. 2019.

OLIVEIRA, Ivan Luís Idalgo. Retinopatia diabética em indivíduos com diabetes e prédiabetes no município de Cambé-PR. 2016. Dissertação (Mestrado em Saúde Coletiva) Universidade Estadual de Londrina, Centro de Ciências da Saúde, Londrina, 2016. Disponível em: http://www.uel.br/pos/saudecoletiva/portal/pages/dissertacoesteses/dissertacoes/ dissertacoes-a-partir-de-2012.php. Acesso em: 2 abr. 2021.

ORGANIZAÇÃO PAN-AMERICANA DA SAÚDE (OPAS). Relatório 30 anos de SUS, que SUS para 2030? Brasília: OPAS, 2018. Disponível em:

http://saudeamanha.fiocruz.br/wp-content/uploads/2019/06/serie-30-anos-sus.pdf. Acesso em: 16 out. 2020.

PAIM, Jairnilson Silva; ALMEIDA FILHO, Naomar de. N. A crise da Saúde Pública e a utopia da Saúde Coletiva. Salvador: Casa da Qualidade Editora, 2000.

PAIVA, Carlos Henrique Assunção; TEIXEIRA, Luiz Antonio. Reforma sanitária e a criação do Sistema Único de Saúde: notas sobre contextos e autores. História, Ciências, Saúde Manguinhos, Rio de Janeiro, v.21, n.1, p.15-35, jan./mar. 2014. Disponível em:

https://www.scielo.br/j/hcsm/a/rcknG9DN4JKxkbGKD9JDSqy/?lang=pt. Acesso em: $17 \mathrm{jul}$. 2020.

PEIRCE, Charles Sanders. Semiótica. 4. ed. São Paulo: Perspectiva, 2008.

PIMENTEL, Joamara de Oliveira. SUS para todos, para pobres ou para ninguém? A visão de estudantes de Educação Física de três universidades públicas do Paraná. 2020. 78 p. Dissertação (Mestrado em Saúde Coletiva) - Universidade Estadual de Londrina, Centro de Ciências da Saúde, Londrina, 2020. Disponível em:

http://www.uel.br/pos/saudecoletiva/portal/pages/dissertacoesteses/dissertacoes/dissertacoesa-partir-de-2012.php. Acesso em: 2 abr. 2021. 


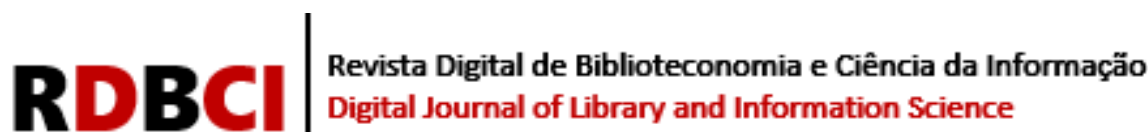

POBLACIÓN, Dinah Aguiar; NORONHA, Daisy Pires. Produção das literaturas "branca" e "cinzenta" pelos docentes/doutores dos programas de pós-graduação em ciência da informação no Brasil. Ciência da Informação, Brasília, v. 31, n. 2, p. 98-106, ago. 2002. Disponível em: http://www.scielo.br/scielo.php?script=sci arttext\&pid=S010019652002000200011\&lng=en\&nrm=iso. Acesso em: 27 jun. 2020.

RABELO, Camila Regina Oliveira; PINTO, Virginia Bentes. Tendências nos estudos de representação temática da informação: uma revisão integrativa dos artigos científicos indexados na Brapci. Em Questão, Porto Alegre, v. 25, n. 2, p. 66-88, 2019. Disponível em: https://seer.ufrgs.br/EmQuestao/article/view/82314/0. Acesso em: 4 out. 2020.

RADIGONDA, Bárbara. Avaliação da atenção às pessoas com hipertensão e ou diabetes no município de Cambé-PR. 2014. 189f. Dissertação (Mestrado em Saúde Coletiva) Universidade Estadual de Londrina, Centro de Ciências da Saúde, Londrina, 2014. Disponível em: http://www.bibliotecadigital.uel.br/document/?code=vtls000189544. Acesso em: 2 abr. 2021.

REFORMA Sanitária. In: Fundação Oswaldo Cruz (FIOCRUZ). SUS de A a Z. Rio de Janeiro: FIOCRUZ. Disponível em: https://pensesus.fiocruz.br/reforma-sanitaria. Acesso em: 11 jul. 2020.

REMONDI, Felipe Assan. Não adesão ao tratamento medicamentoso contínuo e fatores associados: estudo de base populacional. 2012. 91f. Dissertação (Mestrado em Saúde Coletiva) - Universidade Estadual de Londrina, Centro de Ciências da Saúde, Londrina, 2012. Disponível em: http://www.uel.br/pos/saudecoletiva/Mestrado/diss/123.pdf. Acesso em: 2 abr. 2021.

RODRIGUES, Maria Rosemary et al. Tratamento temático da informação na revista discursos fotográficos: palavras-chave ou descritores? In: SEMINÁRIO EM CIÊNCIA DA

INFORMAÇÃO - SECIN, 7., 2017, Londrina. Anais [...] Londrina: UEL, 2017. p. 10631076. Disponível em:

http://www.uel.br/eventos/cinf/index.php/secin2017/secin2107/paper/viewFile/482/331. Acesso em: 28 out. 2018.

SANTOS, Mayara Cristina da Silva. Dor em professores da educação básica: associação com atividade física e tempo vendo televisão. 2020. 175f. Dissertação (Mestrado em Saúde Coletiva) - Universidade Estadual de Londrina, Centro de Ciências da Saúde, Londrina, 2020. Disponível em:

http://www.uel.br/pos/saudecoletiva/portal/pages/dissertacoesteses/dissertacoes/dissertacoesa-partir-de-2012.php. Acesso em: 2 abr. 2021.

SILVA, Cybele Renata Trevisan e. Características antropométricas de crianças de 6 a 23 meses de idade e fatores associados a desvios nutricionais. 2012. 76f. Dissertação (Mestrado em Saúde Coletiva) - Universidade Estadual de Londrina, Centro de Ciências da Saúde, Londrina, 2012. Disponível em: http://www.uel.br/pos/saudecoletiva/Mestrado/res/124.html. Acesso em: 2 abr. 2021.

TAVARES, Paulo César Vieira. Atuação do Ministério Público Estadual de Londrina na área da saúde pública: análise das demandas e atividades. 2010. 99 f. Dissertação (Mestrado em Saúde Coletiva) - Universidade Estadual de Londrina, Centro de Ciências da Saúde, 


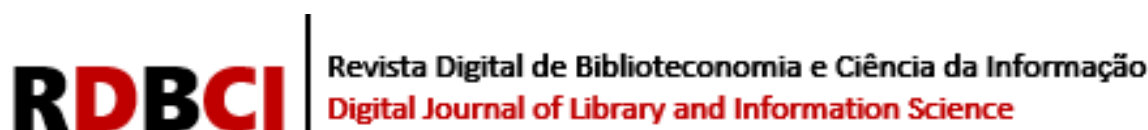

Londrina, 2010. Disponível em: http://www.uel.br/pos/saudecoletiva/Mestrado/diss/111.pdf. Acesso em: 2 abr. 2021.

TEIXEIRA, Sônia Maria Fleury. Retomar o debate sobre a reforma sanitária para avançar o sistema único de saúde (SUS). Revista de Administração de Empresas, São Paulo, v. 49, n. 4, p. 472-480, dez. 2009 . Disponível em:

http://www.scielo.br/scielo.php?script=sci arttext\&pid=S003475902009000400010\&lng=en\&nrm=iso. Acesso em: 27 mar. 2021.

VICTORINO, Marcio de Carvalho; BRÄSCHER, Marisa. Organização da informação e do conhecimento, engenharia de software e arquitetura orientada a serviços: uma abordagem holística para o desenvolvimento de sistemas de informação computadorizados.

DataGramaZero: Revista de Ciência da Informação, Brasília, v. 10, n. 3, p. 1-16, jun. 2009. Disponível em: http://www.brapci.inf.br/index.php/res/v/6517. Acesso em: 29 fev. 2020.

WERNECK, Guilherme. Como se dará a evolução de covid-19 na população que vive em condições precárias? Entrevista especial com Guilherme Werneck. [Entrevista cedida a] INSTITUTO Humanitas Unisinos (IHU). São Leopoldo, RS: UNISINOS, 2020. Disponível em: http://www.ihu.unisinos.br/597542-como-se-dara-a-evolucao-de-covid-19-na-populacaoque-vive-em-condicoes-precarias-entrevista-especial-com-guilherme-werneck-2. Acesso em: 12 jul. 2020. 


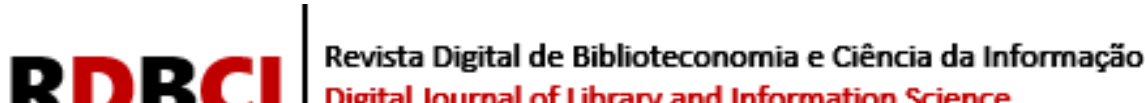 \\ Digital Journal of Library and Information Science}

